Pak. j. sci. ind. res. Ser. A: phys. sci. 2019 62A(2) 124-134

\title{
Review
}

\section{A Review on the Vibration Analysis of Laminated Composite Plate}

\author{
Muhammad Imran*, Rafiullah Khan and Saeed Badshah \\ Department of Mechanical Engineering, International Islamic University, Islamabad, Pakistan
}

(received September 24, 2018; revised November 18, 2018; accepted November 19, 2018)

\begin{abstract}
Composites have played a vital role ranging in the marine structures to agriculutural products. Therefore, proper attention should be given before deploying of composite structures in the service and vibration is one of the most critical factor in the assessment of the structural properties. The purpose of this paper is to review the literature studies on the effect of vibration on composite structures. The literature studies have been focused on the vibration analysis of composite structures without considering the crack or delamination presence in the structure. Literature review is further classified on the basis of methodology i.e experimental, analytical and finite element methods. The work already conducted using these three methods have been discussed. It would be concluded that the vibration is a critical factor to focus.
\end{abstract}

Keywords: vibration, composites, stacking sequences, analytical analysis, modal analysis, experimental vibration analysis

\section{Introduction}

A composite structure is any structure formed from two or more distinct constituent structures. Usually, the new composite structure formed has a distinct property that is different from the chemical characteristics or physical properties of the individual materials used (Imran et al., 2018a). The completed or newly formed composite material has individual layers that are distinguishable from one another. Composite materials have many advantages when compared to conventional materials (Imran et al., 2018b). They are lightweight, cheaper, stiffer, stronger and eco-resistant (Imran et al., 2018c). A good example of a composite material is CarbonFibre-Reinforced Polymers (CFRP). To form a CarbonFibre-Reinforced Polymer (CFRP), two components are required. They include reinforcement and a matrix. The reinforcement needed is achieved through the carbon-fibre. It is the reinforcement of the carbon-fibre that gives the required strength to the composite material being formed. The matrix on the other hand provides bonding between the reinforced materials. A good example of a matrix is epoxy (made from polymer resin) (Bakis et al., 2002; Dökmeci, 1980).

Composite laminates are preferred due to their many advantages such as their high-strength, bending stiffness, resistant to expansion, etc. Usually, composite laminates are formed from a hybrid of fibre-matrix layers. For

*Author for correspondence;

E-mail: Muhammad.imran@iiu.edu.pk example, the fibre usually consists of such materials as boron, or glass while the matrix consist of such materials as aluminum or epoxy (Gürdal et al., 1999).

Undoubtedly, composite materials have gained much attention to designers in almost every field of simple engineering applications to complex structures (Imran et al., 2018a; 2018b; 2018c; Imran, 2015). Ranging from ship building to aerospace industry, composite materials are preferred due to their superior mechanical, electrical and physical properties (Abbas et al., 2016; Friedrich and Almajid, 2013).

Composite laminates are formed by stacking different laminates. Stacking sequence is the arrangement of laminated layers at a specific directions and orientations (Pagano and Pipes, 1971). Stacking sequence optimization requires the least number of layers with maximum fibre quality of each laminated layer (Ghiasi et al., 2010). Different stacking sequence imparts different properties to the structural components (Muhammad Imran, 2018d).

Every composite structure experiences free and forced vibration during their service periods (Sajid, 2015). The consequences of vibration imposed to composite structures have a huge impact in the overall performance of the structure ranging from minor issue to significant damage incidences to the structure (Cavallo et al., 2017). A comprehensive review study of vibration analysis of composite laminated structures is lacking. The objective 
of this paper is to present a comprehensive review of the state of the art studies on the vibration analysis of composite plate. Only the research work in the English language are reviewed in this review article. Particular attention is given to composite laminates without considering the effect of the cracks or delamination.

Techniques for analysis. The literature studies has been classified according to the techniques adapted i.e. analytical, experimental and finite element analysis. The next sections critically describe the prominent studies according to the above theme.

Analytical techniques. Reddy et al. (2013) investigated the behaviour of vibration and buckling on composite laminated plate to find out how vibration characteristics of stacking sequence influences the behaviour of composite laminated plates under different modular ratios, aspect ratios and thickness ratios. Using the ANSYS software, finite model was developed with the aid of APDL coding to analyze the behaviour and characteristics of composite laminated plate under free vibration and buckling. Based on his investigation he concluded that vibration characteristics of stacking sequence influences the behaviour of composite laminated plates in the following ways:

a. Any increase in the modular ratio also causes the frequency of the laminated plate to increase

b. Increase in thickness ratio rather caused buckling load to decrease. The aspect ratio had a reverse response.

c. Clamped plates have higher non-dimensional frequency value than non-clamped plates.

Zhang et al. (2015) conducted free vibration analysis of functionally graded carbon nanotube reinforced composite plate first order shear deformation theory and Ritz method. They also investigated the influence of thickness to weight ratio and carbon volume fraction on plate's vibration behaviour. They concluded that non-dimensional fundamental frequency of plate with $\mathrm{CC}$ boundary condition.

Kishore and Behera (2015) investigated a base line study for determining the influence of layer-wise sequence on dynamic properties of composite propeller blade. In order to analyze the impact of the frequency and the profile of the propeller blade which was in cantilever model, a calculation was done via finite element method (FEA) technique. The ply angel of orientation was also considered during the calculation of the vibration characteristics of the propeller. They observed that the propeller blade performed better than metallic blade when the symmetric ply stacking sequence was employed. The general stiffness of the propeller blade and other properties kept changing depending on the position of the mid-plane, number of layer, orientation of fibre and the yield of the stacking sequence laminate. The torsion and flexural frequencies of the stacking sequence $( \pm 45 / 0) 11,(45 /(-45) / 0) 11,(0 / \pm 45)$ increased when the layers were increased from 4 to 8 . The torsion and bending frequencies of the composite obtained the highest frequency when the stacking sequence $( \pm(45 / 0) /$ $( \pm 45)) 7(0 / 90) 2$ was applied.

It is observed however that Kishore and Behera (2015), failed to investigate the effects of vibration characteristics of stacking sequence on conventional propeller blades under asymmetric ply stacking sequence. The results were therefore, only valid for symmetric ply stacking sequence.

Mlyniecet et al. (2014) investigated the non-linear characteristics of carbon/epoxy composites subjected to thickness of the laminate, layer-wise sequence and thermal aging. With the use of dynamic mechanical analysis and laser dopler vibrometry, they measured varying behaviours of unidirectional laminates and quasi-isotropic laminates at varying degrees of thickness. The results obtained indicated that unidirectional composites modal damping factors have an upward tendency after aging while quasi-isotropic plates have a declining tendency. It was observed, however, that multidirectional laminates were not considered in their experiment. It was therefore, impossible to compare and contrast how stacking sequence influence thermal aging of unidirectional and multidirectional laminates.

Ratnaparkhi and Sarnobat (2013) did an investigation on the vibration behaviour of composite plates. They argued that due to extensive use of composite plates, they are likely to develop fractures as a result of vibration characteristics. Their objective was to find a way of minimizing vibration in order to enhance the safety of composite plates. In order to do this, they used a handlayup method to manufacture a fibre material consisting of glass and epoxy. They subjected the fibre to freefree boundary conditions. With the help of the modal analysis technique, they were able to obtain their natural frequencies. The results obtained validated the FEA results which was done using ANSYS. They observed that fractures occurred more rapidly in the structures 
(glass/epoxy composite plate) when subjected to resonant vibrations. It was observed, however, that the research did not experiment under clamped boundary conditions but only under free-free boundary conditions.

Samadpour et al. (2015) investigated vibration characteristics of thermally buckled Shape Memory Alloy (SMA) composite sandwich hybrid plate. First-order Shear Deformation Theory (FSDT) along with von Karman geometric nonlinearity using Hamilton principle was used to come up with dynamical equations of motion for the sandwich plate. Also, the buckling temperature and primary natural frequency was calculated using Galerkin Weighted Residual Method. Results they obtained indicated that recovery of stress generation causes SMA fibres to have major impact on post buckling deflection and natural frequency.

Anlas and Elbeyli (2002) investigated non-linear vibration properties of rectangular plate. The rectangular plate was considered as simply supported and was subjected to transverse harmonic excitation by using one-to-one internal resonance parameter. They investigated the stability of the structure using bifurcation method.

Biswal et al. (2016) investigated free vibration properties on fibre glass/epoxy laminated composite shells. They conducted analytical and experimental techniques on cylindrical shells. They used Green Lagrange's strain displacement relationship. They concluded that frequencies decrease with increase in temperature and moisture content.

Dimarogonas and Massouros (1981) did an analysis on circumferential crack to find its effect on the non-linear vibration behaviour of a shaft. It was observed that natural frequencies have inverse relation with crack depth. They also found that natural frequency of a shaft is strongly dependent upon the depth of crack. However, they didn't find the dynamic behaviour in a complex geometry of shaft.

Giunta et al. (2013) conducted free vibration analysis of composite simply supported beams. They employed Euler-Bernoulli's and Timoshenko's theories to find the influence of length to thickness ratios, aspect ratios and material properties on the natural frequencies and mode shapes of the beam along with accuracy of the proposed theories. Square beam with 0/90 stacking sequence for beam and last four mode shapes were analyzed. The impact of length to thickness ratio was investigated and found that higher order models will be needed for natural frequencies prediction subjected to torsion. Effect of the aspect ratio analysis concluded that the first three natural frequencies have different response as shown in Fig. 1.

Bending deformation was observed on first two modes on xy and xz planes in case of square cross section. The natural frequency of the third mode on $x z$ plane is actually dimensionless and insensitive to the aspect ratio of the beam.

Results obtained from the current research article were then compared with the three dimensional (3-D) finite element method solution obtained from ANSYS software (Madenci and Guven, 2015). Classical theories solution were not accurate with the FEM solution predicted by Madenci and Guven (2015) and 10 to 14\% difference was still observed.

Carrera et al. (2012) conducted dynamic analysis for pre-stressed laminated composite plate subjected to inplane mono-axial, biaxial, shear and combined loadings. Plate geometry is shown in Fig. 2.

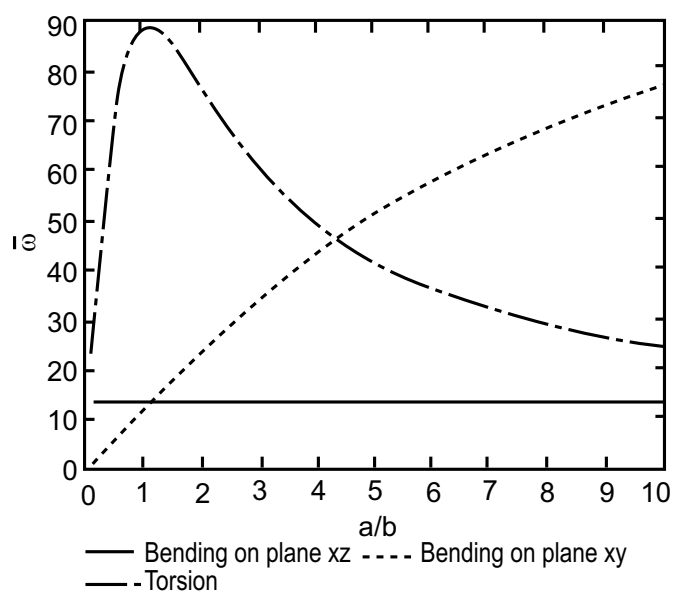

Fig. 1. Variation of the first three mode shapes (Giunta et al., 2013).

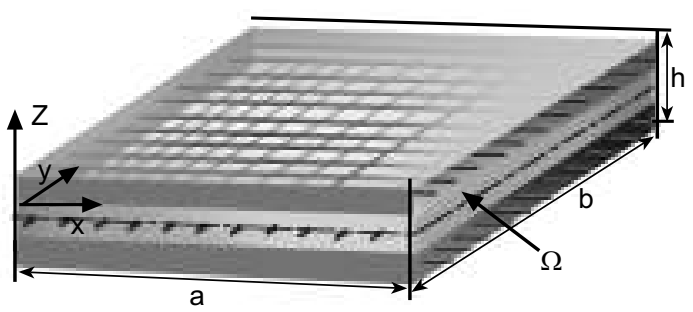

Fig. 2. Reference system and plate geometry (Carrera et al., 2012). 
Thin plate theory also called shear deformation theory, equivalent single layer and layer-wise theories were used. It was concluded that plate frequencies would vary in the presence of shear loads and natural frequencies would gradually decrease if load would be increased as shown in Fig. 3. Natural frequencies for stacking sequences $0 / 60 / 90 / 60 / 0$ would first increase upon loading and then will decrease smoothly.

Chandra and Chopra (1992) investigated free vibration characteristics using Galerkin method subjected to extension-twist and bending-twist coupling. They tested the thin walled box beams. Theoretical and experimental techniques were implemented. Results obtained from theoretical and experimental methods were correlated. Bending-shear coupling greatly affected the vibration properties than extension shear couplings.

Hwu et al. (2017) conducted an analytical analysis to find the free vibration characteristics of composite sandwich plates and cylindrical shells. Modified firstorder-shear-deformation theory was employed to find the analytical results. Navier's solution, Levy's solution and Ritz method was incorporated to find the natural frequencies of sandwich plate and cylindrical shell. It was concluded that as the thickness of the sandwich face reduced, natural frequency increased.

Yang and Chiu (1993) developed an analytical technique to find vibration properties of composite laminated structure by embedding the piezoelectric materials. Electrical insulation problems and piezoelectric material cracking problems were prevented by using ultrasonic c-scan test. An analytical model was proposed for

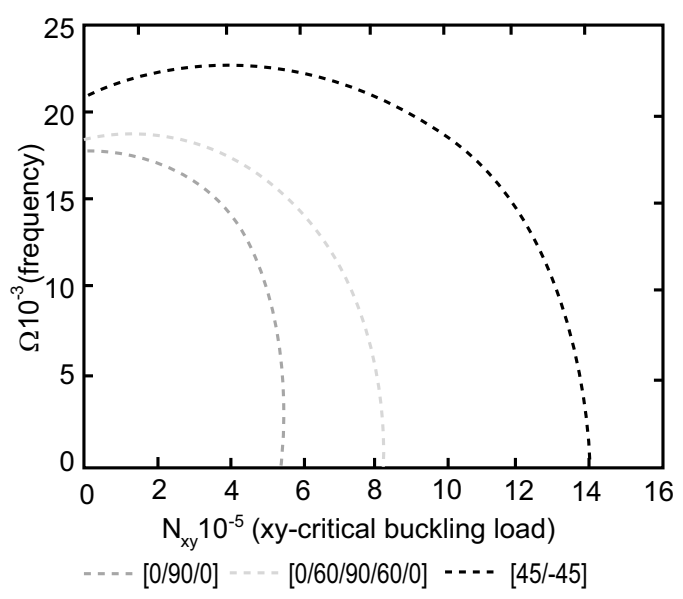

Fig. 3. Load caused the frequencies first to increase then to decrease (Carrera et al., 2012). composite laminate subjected to embedding of piezoelectric material as shown in Fig. 4. Using this model, the natural frequencies and mode shapes of the material were predicted. Based on the small strain and linear stress-strain assumptions, in shear deformation theory, it was concluded that natural frequencies, with piezoelectric materials, are greater than those without piezoelectric material but with small difference.

Chandrashekhara et al. (1990) conducted free vibration analysis tests to find the response of symmetrically laminated composite beam. First order shear deformation theory was used for mathematical formulation of multilayered composite beam (Fig. 5).

It was concluded that shear deformation theory and classical lamination theory have similar results for long-thin beams as shown in Table 1. Furthermore, it was concluded that an increase in fibre orientation, frequencies decreased.

Hodges et al. (1991) did an investigation on graphite/ epoxy composite beam using numerical integration method and mixed finite element technique. It was concluded that extension bending shear mode is a function of both geometric configuration and material.

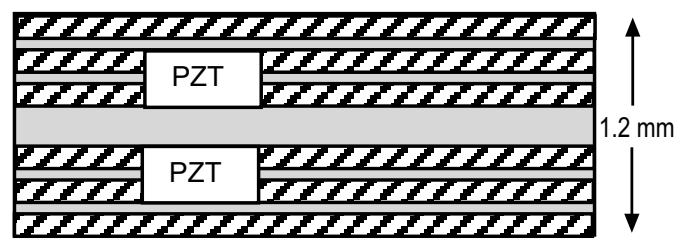

Fig. 4. Geometry of structure proposed by Yang (Yang and Chiu, 1993).

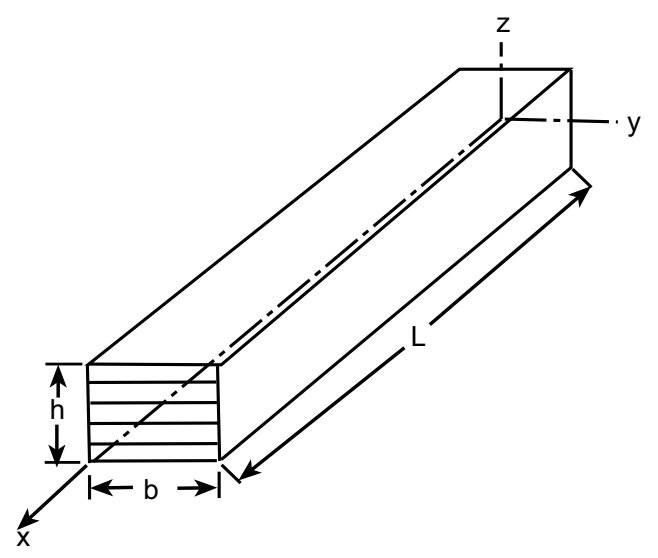

Fig. 5. Composite beam used for free vibration analysis (Chandrashekhara et al., 1990). 
Table 1. Natural frequencies with length to thickness ratio and mode numbers subjected to simply supported orthotropic epoxy composite beam (Chandrashekhara et al., 1990)

\begin{tabular}{llll}
\hline \hline \multirow{2}{*}{$\begin{array}{l}\text { Length to thickness } \\
\text { ratio }\end{array}$} & $\begin{array}{l}\text { Mode } \\
\text { number }\end{array}$ & \multicolumn{2}{c}{ Frequency $(\mathrm{kHz})$} \\
\cline { 3 - 4 } 120 & 1 & 0.051 & 0.051 \\
$(\mathrm{~h}=0.25)$ & 2 & 0.203 & 0.203 \\
& 3 & 0.457 & 0.457 \\
& 4 & 0.812 & 0.812 \\
& 5 & 1.269 & 1.269 \\
15 & 1 & 0.755 & 0.813 \\
$(\mathrm{~h}=1)$ & 2 & 2.548 & 3.250 \\
& 3 & 4.716 & 7.314 \\
& 4 & 6.960 & 13.002 \\
& 5 & 9.194 & 20.316 \\
\hline \hline
\end{tabular}

Ferreira et al. (2005) did an analysis to find the vibration response using First Order Shear Deformation Theory (FSDT) in thick symmetric composite laminated plate for radial basis function. It was concluded that clamped skew plates showed better results for free vibration than those for simply supported plate.

Marur and Kant (1996) did vibration simulation for fibre reinforced composite and sandwich beam using Higher Order Beam Theories (HOBT). It was concluded that higher order model have higher values of frequencies than first order models for thin beams. For thick sandwich beams, higher order model have lower values of frequencies than first order models.

Liu and Huang (1996) used First Order Shear Deformation Theory with argumentation of von Karman strains. They find the natural frequencies on laminated composite plate subjected to temperature change. It was concluded that the non-dimensional fundamental frequencies change linearly as the temperature changes.

Dey and Ramachandra (2017) conducted non-linear vibration examination subjected to laminated composite shells using Donnel Type Shell Theory with first order shear deformation theory. Frequency amplitude response showed more softening and uniform nature with increasing trend in geometric imperfections.

Tong (1993) find the frequencies of composite laminated conical shells using Donnel-type governing equations using the power-series methodology. It was concluded that lower value of frequency parameter was observed for larger extension-bending coupling for a given wave number.

Lee et al. (1987) did an investigation on composite rectangular plates which tends to show special and general orthotropic parameters. Rayleigh principle and Classical Plate Theory was used for the determination of natural frequencies and mode shapes of composite rectangular plates. Numerical results were concluded, for higher order modes, Rayleigh quotient was less accurate.

Nabi and Ganesan (1994) used FSDT to find the vibration characteristics of graphite epoxy laminated composite beams structure. Mode shapes obtained from the investigation show that first two natural frequencies have incliding effect on length-wise and chord-wise directions. However, frequencies are decreasing with an increase in fibre orientation angle.

Hwu et al. (2004) found the frequency response of composite sandwich beams using analytical closedform expressions for forced vibration using of MATLAB/ Simulink. It was concluded that rotation angle is of utmost importance in this analysis and that without rotation angle, frequency response of the sandwich beams is none.

Singh et al. (2002) did an investigation using the principle of Higher First Order Shear Deformation theory to find the vibration characteristics of laminated composite cylindrical panels. Lower value of sensitivity is observed for changes in Poisson's ratio. Cazzani et al. (2016) used First Order Shear Deformation Theory to derive governing equations for modal analysis of laminated plate. Lee et al. (2016) find the influence of fibre orientation on the vibration characteristics of carbon-fibre-reinforced-plastic plate.

Experimental techniques. Biswal et al. (2016) investigated free vibration properties on fibre glass/epoxy laminated composite shells. Analytical and experimental techniques were conducted using cylindrical shells as shown in Fig. 6. Green Lagrange's strain displacement relationship was utilized. They concluded that frequencies decrease upon an increase in the values of temperature and moisture content. Clamped-free-clamped-free boundary conditions showed highest values of natural frequencies than other boundary conditions as shown in Fig. 7.

Rath and Sahu (2012) conducted an analysis to find the vibration properties of woven fibre laminated composite 
plates under hygrothermal conditions (Fig. 8). First Order Shear Deformation Theory (FSDT) was used as governing equation. Tests subjected to simply supported and clamped-supported boundary conditions were conducted.

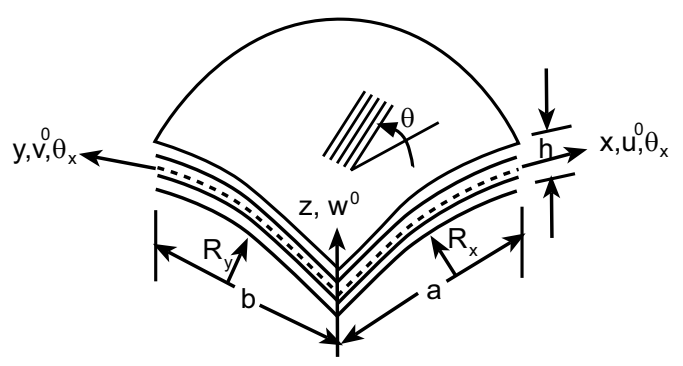

Fig. 6. Laminated cylindrical shell (Biswal et al., 2016).

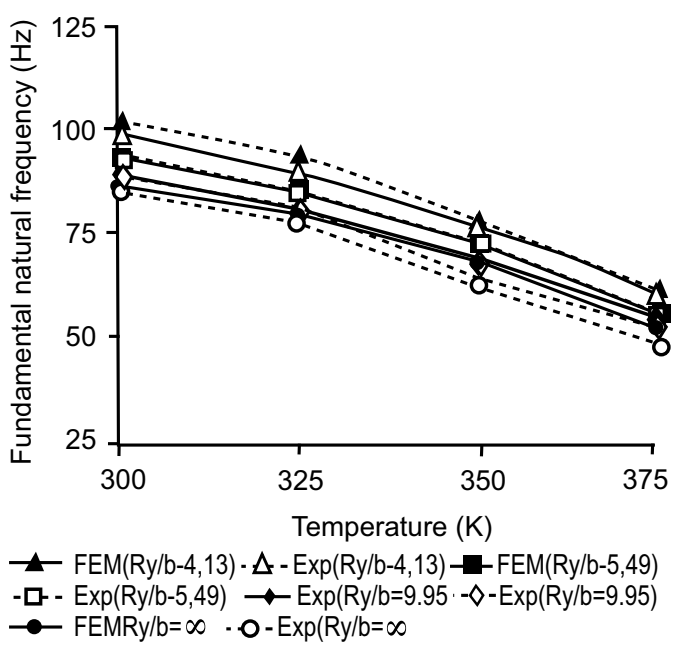

Fig. 7. Temperature effect on fundamental frequencies of cylindrical shell (Biswal et al., 2016).

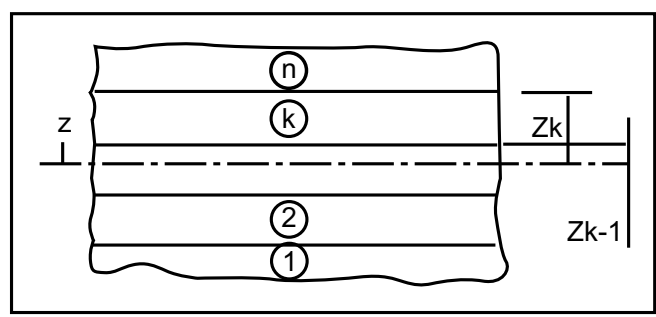

Fig. 8. Geometry of n-layered laminate (Rath and Sahu, 2012).
Analytical and experimental results showed that four sides clamped (CCCC) boundary conditions showed higher values of vibration frequencies than simply supported due to clamping effects and better elastic rigidities constraints as shown in Fig. 9.

Zhang et al. (2015) conducted free vibration analysis reinforced composite plate using First Order Shear Deformation Theory and Ritz method. Influence of thickness to weight ratio and carbon volume fraction on plate's vibration behaviour was also investigated. It was concluded that non-dimensional fundamental frequency of plate with clamped-clamped boundary condition is the highest.

Khare et al. (2004) investigated free vibration of laminated and sandwich composite laminated plate subjected to higher order facet shell elements. They concluded that for composite laminates, First Order Shear Deformation Theory and Higher Order Shear Deformation theory have small difference while in case of sandwich panels, there is significant difference in frequencies and the difference increases as the laminate thickness increases and results were compared with Putcha and Reddy (1984). Teter and Gawryluk (2016) conducted experiments to find the modal analysis of rotor and Savin et al. (2016) investigated the vibration analysis of various lignocelluloses based composite materials. They found the influence of material structures on the natural modes.

Khan et al. (2011) conducted vibration analysis on carbon fibre reinforced polymer composite with multiple carbon nanotubes by free and forced vibration tests using experimental setup. It was concluded that lower natural frequency was observed after incorporation of carbon nanotubes in the composite however, damping

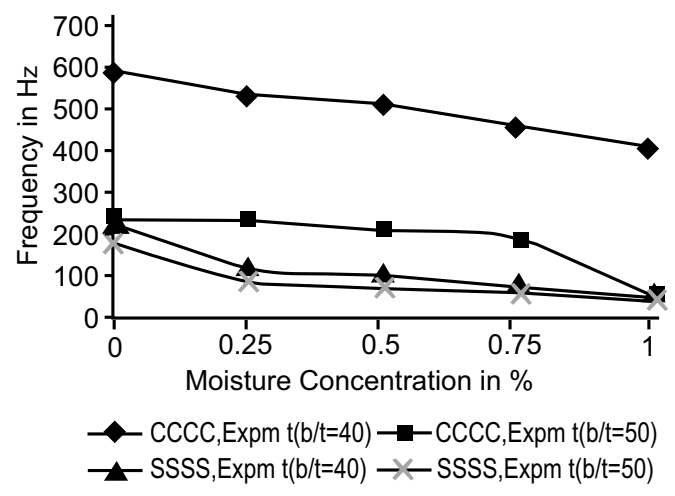

Fig. 9. Frequencies comparison for $\mathrm{CCCC}$ and SSSS boundary conditions (Rath and Sahu, 2012). 
characteristics of the composite was increased by the addition of carbon nanotubes.

Finite element method. Gunay and Timarci (2012) found natural frequencies and mode shapes of laminated cantilever boxed beams using FEM (Finite Element) tool ANSYS subjected to circumferentially uniform stiffness and circumferentially asymmetric stiffness as shown in Fig. 10.

They concluded that ANSYS results have lower values as compared to experimental results obtained by Chandra and Chopra (1992).

Chandrashekhara and Bangera (1992) conducted free vibration analysis of laminated composite beam using finite element method based on shear deformation theory as shown in Fig. 11.

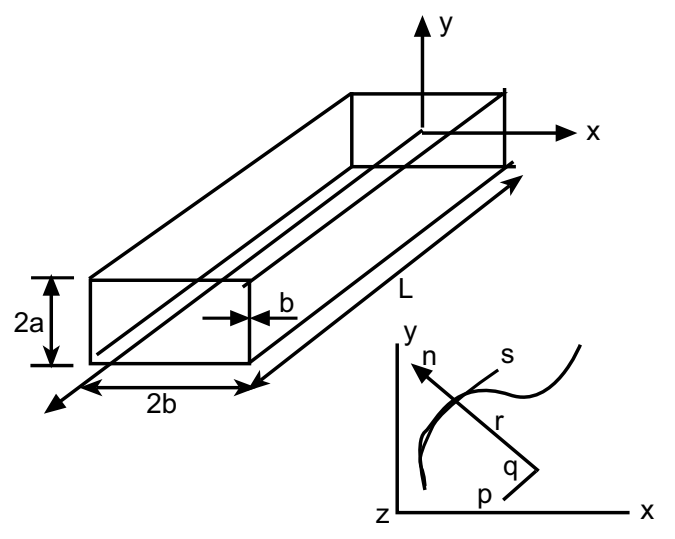

Fig. 10. Geometry of the beam (Gunay and Timarci, 2012).

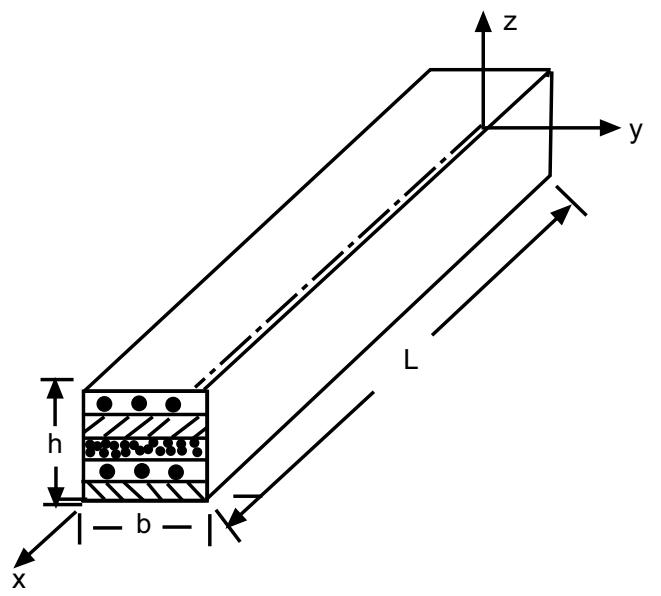

Fig. 11. Geometry of laminated composite beam (Chandrashekhara and Bangera, 1992).
Chandrashekhara and Bangera (1992) concluded that the values of shear deformations show increasing trends greater for the higher modes as shown in Table 2.

Eslami et al. (2017) conducted finite element analysis to predict the mode shapes and natural frequencies and buckling behaviour of long rectangular composite plates and compared the vibration results with Rayleigh Ritz method. Plate was subjected to clamped and simply supported boundary conditions. It was concluded that natural frequencies of a plate converge once the aspect ratio reduces below 0.25 as shown in Fig. 12. However, no dynamic or transient vibration analysis was done to further verify the results obtained from Ritz method and finite element code using Nastran/Patran.

Bicos and Springer (1989) used laminated fibre reinforced plates and shells to find the free vibration characteristics. A finite element method was used to find the free damped vibration characteristics of laminated plates and shells. Computer code was developed for analysis of free damped and undamped vibration

Table 2. Effect of ply orientation on non-dimensional frequencies (Chandrashekhara and Bangera, 1992)

\begin{tabular}{llll}
\hline \hline Mode & $90 / 90 / 0 / 90$ & $45 /-45 / 45 /-45$ & $30 / 50 / 30 / 50$ \\
\hline 1 & 3.7244 & 1.9807 & 2.2526 \\
2 & 8.9275 & 5.2165 & 5.8624 \\
3 & 15.3408 & 9.6912 & 10.7609 \\
4 & 22.3940 & 10.5345 & 11.9506 \\
5 & 24.3155 & 15.0981 & 16.5747 \\
\hline \hline
\end{tabular}

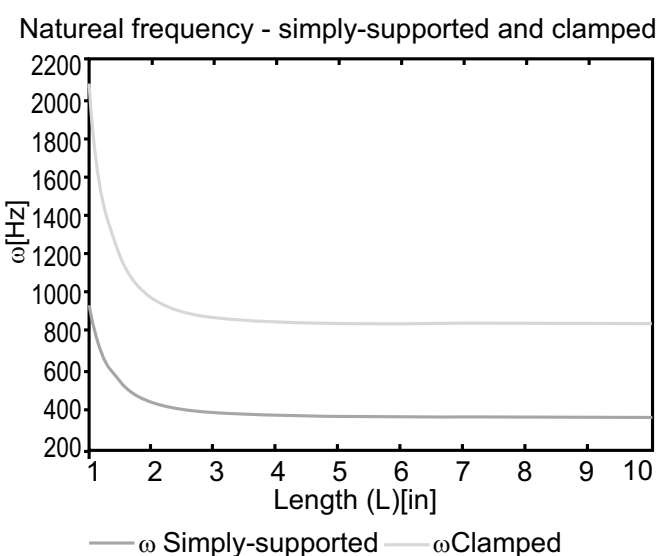

Fig. 12. Relationship between mode shape and natural frequencies for simply supported and clamped plate (Eslami et al., 2017). 
properties of flat and cylindrical panels. This code would not be better to apply for isotropic materials.

Shrigandhi and Deshmukh (2016) conducted modal analysis of composite sandwich panels using FEA. Ribeiro and Petyt (1999) did vibration analysis of composite laminated plate using finite element and the harmonic balance methods. Hierarchical finite element method requires far fewer degree of freedoms than hversion of the same finite element methods.

Kuo and Shiau (2009) did an analysis to find the vibration properties on composite laminated plate using finite element method. More the fibres concentrated in mid portion of plate, more the buckling load and natural frequencies. Critical buckling load will increase if more fibres are concentrated in outer part of the plate.

Numayr et al. (2004) used finite difference method to find the vibration characteristics of symmetric and angle-ply laminated composite plate. It was concluded that fibre orientation has a greater impact on the natural frequencies of angle-ply laminated plate however, at $45^{\circ}$ fibre orientation, greatest natural frequency response was obtained.

Four sides clamped (CCCC) boundary conditions showed higher values of vibration frequencies than simply supported due to clamping effects and better elastic rigidities constraints. Non-dimensional fundamental frequency of plate with clamped-clamped boundary condition is the highest. For composite laminates, difference between the first order and shear deformation theories was of small value while in case of sandwich panels as shown in Table 5, there is significant difference in frequencies and the difference increases as the laminate thickness increases. It was concluded that natural frequencies of a plate converge once the aspect ratio reduces below 0.25 . It was concluded that fibre orientation has a greater impact on the natural frequencies of angle-ply laminated plate however at $45^{\circ}$ fibre orientation, greatest natural frequency response was obtained. Lower natural frequency was observed after incorporation of carbon nanotubes in the composite however damping characteristics of the composite was increased by the addition of carbon nanotubes.

CFCF (clamped-free-clamped-free) boundary conditions showed highest values of natural frequencies than CFFF (clamped-free-free-free) and SFSF (supported-freesupported-free) boundary conditions. Frequencies are decreasing with an increase in fibre orientation angle. It concluded that higher order model have higher values of frequencies than first order models for thin beams. For thick sandwich beams, higher order model have lower values of frequencies than first order models. First-order-shear-deformation theory in modified format was employed to find the analytical results. Navier's solution, Levy's solution and Ritz method was used to find the natural frequencies of sandwich plate and cylindrical shell. It was concluded that as the thickness of the sandwich face reduced, natural frequency increased.

\section{Conclusion}

Dynamic behaviour in composite plate structures are of utmost interest to the scientific and engineering societies for many years. The composite structures are widely being used in almost every industry from simple mechanisms to broad range of aviation products. The current research work is to review the past work along with prediction of the linear and nonlinear behaviour of parametrically excited composite structures. Therefore, analyzing the dynamic response experimentally, analytically and finite theoretically, of plate structures with under various loading conditions will aid in understanding and explaining the behaviour of more complex, real structures under various loading conditions. This review paper will provide researchers a unique knowledge-base about the vibration of composite structures.

\section{Acknowledgement}

The author acknowledge the support from Department of Mechanical Engineering, International Islamic University, Islamabad, Pakistan.

Conflict of Interest. The authors declare no conflict of interest.

\section{References}

Abbas, S., Abbas, Z., Pasha, R.A. 2016. Analytical estimation and numerical simulation of vibration based Piezoelectric energy harvesters. International Journal of Science, Engineering and Innovative Research, 13: 1-9.

Anlas, G., Elbeyli, O. 2002. Nonlinear vibrations of a simply supported rectangular metallic plate subjected to transverse harmonic excitation in the presence of a one-to-one internal resonance. Nonlinear Dynamics, 30: 1-28. 
Bakis, C., Bank, L.C., Brown, V., Cosenza, E., Davalos, J., Lesko, J., Machida, A., Rizkalla, S., Triantafillou, T. 2002. Fiber-reinforced polymer composites for construction-state-of-the-art review. Journal of Composites for Construction, 6: 73-87.

Bicos, A.S., Springer, G.S. 1989. Analysis of free damped vibration of laminated composite plates and shells. International Journal of Solids and Structures, 25: 129-149.

Biswal, M., Sahu, S., Asha, A. 2016. Vibration of composite cylindrical shallow shells subjected to hygrothermal loading-experimental and numerical results. Composites Part B: Engineering, 98: 108-119.

Carrera, E., Nali, P., Lecca, S., Soave, M. 2012. Effects of in-plane loading on vibration of composite plates. Shock and Vibration, 19: 619-634.

Cavallo, T., Zappino, E., Carrera, E. 2017. Free-vibration analysis of space vehicle structures made by composite materials. Composite Structures, 183: 53-62.

Cazzani, A., Rizzi, N.L., Stochino, F., Turco, E. 2016. Modal analysis of laminates by a mixed assumedstrain finite element model. Mathematics and Mechanics of Solids, 23: 99-119.

Chandra, R., Chopra, I. 1992. Experimental-theoretical investigation of the vibration characteristics of rotating composite box beams. Journal of Aircraft, 29: 657-664.

Chandrashekhara, K., Bangera, K.M. 1992. Free vibration of composite beams using a refined shear flexible beam element. Computers and Structures, 43: 719-727.

Chandrashekhara, K., Krishnamurthy, K., Roy, S. 1990. Free vibration of composite beams including rotary inertia and shear deformation. Composite Structures, 14: 269-279.

Dey, T., Ramachandra, L.S. 2017. Non-linear vibration analysis of laminated composite circular cylindrical shells. Composite Structures, 163: 89-100.

Dimarogonas, A., Massouros, G. 1981. Torsional vibration of a shaft with a circumferential crack. Engineering Fracture Mechanics, 15: 439-444.

Dökmeci, M. 1980. Vibration analysis of laminated composites. The Journal of the Acoustical Society of America, 68: S116-S116.

Eslami, H., Khalili, N., Gandi, U.S. 2017. Vibration of long rectangular composite plates and buckling of such plates under shear and axial loads. $58^{\text {th }}$ AIAA/ ASCE/AHS/ASC Structures, Structural Dynamics, and Materials Conference, pp. 1987.

Ferreira, A., Roque, C., Jorge, R. 2005. Free vibration analysis of symmetric laminated composite plates by FSDT and radial basis functions. Computer Methods in Applied Mechanics and Engineering, 194: 4265-4278.

Friedrich, K., Almajid, A.A. 2013. Manufacturing aspects of advanced polymer composites for automotive applications. Applied Composite Materials, 20: $107-128$.

Ghiasi, H., Fayazbakhsh, K., Pasini, D., Lessard, L. 2010. Optimum stacking sequence design of composite materials Part-II: Variable stiffness design. Composite Structures, 93: 1-13.

Giunta, G., Biscani, F., Belouettar, S., Ferreira, A., Carrera, E. 2013. Free vibration analysis of composite beams via refined theories. Composites Part B: Engineering, 44: 540-552.

Gunay, M.G., Timarci, T. 2012. International scientific conference (UNITECH), pp. 102-106.

Gürdal, Z., Haftka, R.T., Hajela, P. 1999. Design and Optimization of Laminated Composite Materials, 352 pp., John Wiley \& Sons, USA.

Hodges, D.H., Atilgan, A.R., Fulton, M.V., Rehfield, L.W. 1991. Free-vibration analysis of composite beams. Journal of the American Helicopter Society, 36: 36-47.

Hwu, C., Hsu, H.W., Lin, Y.H. 2017. Free vibration of composite sandwich plates and cylindrical shells. Composite Structures, 171: 528-537.

Hwu, C., Chang, W.C., Gai, H.S. 2004. Vibration suppression of composite sandwich beams. Journal of Sound and Vibration, 272: 1-20.

Imran, M., Khan, R., Badshah, S. 2018a. Finite element analysis to investigate the influence of delamination size, stacking sequence and boundary conditions on the vibration behavior of composite plate. Iranian Journal of Materials Science and Engineering, 16: 11-21.

Imran, M., Khan, R., Badshah, S. 2018b. A review on the effect of delamination on the performance of composite plate. Pakistan Journal of Scientific and Industrial Research Series A: Physical Sciences, 61: 173-182.

Imran, M., Khan, R., Badshah, S. 2018c. Vibration analysis of cracked composite laminated plate and 
beam structures. Romanian Journal of Acoustics and Vibration, 15: 3-13.

Imran, M., Khan, R., Badshah, S. 2018d. A review on the effect of delamination on the performance of composite plate. Pakistan Journal of Scientific and Industrial Research Series A: Physical Sciences, 61A: $84-90$.

Imran, M. 2015. Pre-stress and free vibration optimization of composite ocean current turbine blade. International Journal of Science, Engineering and Innovative Research, 3: 1-5.

Khan, S.U., Li, C.Y., Siddiqui, N.A., Kim, J.-K. 2011. Vibration damping characteristics of carbon fiberreinforced composites containing multi-walled carbon nanotubes. Composites Science and Technology, 71: 1486-1494.

Khare, R.K., Kant, T., Garg, A.K. 2004. Free vibration of composite and sandwich laminates with a higherorder facet shell element. Composite Structures, 65: 405-418.

Kishore, M.L.P., Behera, R.K. 2015. Base line study for determination of effect of stacking sequence on vibration characteristics of composite propeller blade. Aquatic Procedia, 4: 458-465.

Kuo, S.-Y., Shiau, L.-C. 2009. Buckling and vibration of composite laminated plates with variable fibre spacing. Composite Structures, 90: 196-200.

Lee, H., Lim, S., Chow, S. 1987. Free vibration of composite rectangular plates with rectangular cutouts. Composite Structures, 8: 63-81.

Lee, S.K., Kim, M.W., Park, C.J., Chol, M.J., Kim, G., Cho, J.-M., Choi, C.-H. 2016. Effect of fibre orientation on acoustic and vibration response of a carbon fibre/epoxy composite plate: Natural vibration mode and sound radiation. International Journal of Mechanical Sciences, 117: 162-173.

Liu, C.-F., Huang, C.-H. 1996. Free vibration of composite laminated plates subjected to temperature changes. Computers \& structures, 60: 95- 101.

Madenci, E., Guven, I. 2015. The finite element method and applications in engineering using ANSYS $^{\circledR}$. 657 pp., $2^{\text {nd }}$ edition, Springer, USA.

Marur, S., Kant, T. 1996. Free vibration analysis of fiber reinforced composite beams using higher order theories and finite element modelling. Journal of Sound and Vibration, 194: 337-351.

Mlyniec, A., Korta, J., Kudelski, R., Uhl, T. 2014. The influence of the laminate thickness, stacking sequence and thermal aging on the static and dynamic behavior of carbon/epoxy composites. Composite Structures, 118: 208-216.

Nabi, S.M., Ganesan, N. 1994. A generalized element for the free vibration analysis of composite beams. Computers \& Structures, 51: 607-610.

Numayr, K.S., Haddad, R.H., Haddad, M.A. 2004. Free vibration of composite plates using the finite difference method. Thin-Walled Structures, 42: 399-414.

Pagano, N., Pipes, R.B. 1971. The influence of stacking sequence on laminate strength. Journal of Composite Materials, 5: 50-57.

Putcha, N.S., Reddy, J.N. 1984. A mixed shear flexible finite element for the analysis of laminated plates. Computer Methods in Applied Mechanics and Engineering, 44: 213-227.

Rath, M., Sahu, S. 2012. Vibration of woven fibre laminated composite plates in hygrothermal environment. Journal of Vibration and Control, 18: 1957-1970.

Ratnaparkhi, S.U., Sarnobat, S. 2013. Vibration analysis of composite plate. International Journal of Modern Engineering Research (IJMER), 3: 377-380.

Reddy, B.S., Reddy, M.R.S., Reddy, V.N. 2013. Vibration analysis of laminated composite plates using design of experiments approach. International Journal of Engineering Science and Technology, 2: 40-49.

Ribeiro, P., Petyt, M. 1999. Non-linear vibration of composite laminated plates by the hierarchical finite element method. Composite Structures, 46: 197-208.

Sajid, R.Z.A. 2015. Buckling analysis of an ocean current turbine blade. International Journal of Science, Engineering and Innovative Research, 2: 6-11.

Samadpour, M., Sadighi, M., Shakeri, M., Zamani, H.A. 2015. Vibration analysis of thermally buckled SMA hybrid composite sandwich plate. Composite Structures, 119: 251-263.

Savin, A., Curtu, I., Stanciu, M.D. 2016. Modal analysis of lignocelluloses based composite materials. The 40 th International Conference of Mechanics of solid, Acoustics and Vibration and the $6^{\text {th }}$ International Conference on "Advanced Composite Materials Engineering" COMAT 2016 \& ICMSAV 2016 Brasov, Romania, 24-25 November 2016. 
Shrigandhi, G., Deshmukh, P. 2016. Modal Analysis of Composite Sandwich Panel. International Journal of Current Engineering and Technology, Special Issue-4 (March 2016).

Singh, B., Yadav, D., Iyengar, N. 2002. Free vibration of composite cylindrical panels with random material properties. Composite Structures, 58: 435-442.

Teter, A., Gawryluk, J. 2016. Experimental modal analysis of a rotor with active composite blades. Composite Structures, 153: 451-467.
Tong, L. 1993. Free vibration of composite laminated conical shells. International Journal of Mechanical Sciences, 35: 47-61.

Yang, S., Chiu, J. 1993. Smart structures-vibration of composites with piezoelectric materials. Composite Structures, 25: 381-386.

Zhang, L., Lei, Z., Liew, K. 2015. Free vibration analysis of functionally graded carbon nanotube-reinforced composite triangular plates using the FSDT and element-free IMLS-Ritz method. Composite Structures, 120: 189-199. 